\title{
Technology Transfer in Academia-Industry Collaborations
}

\section{Sascha Griffiths \& Florian Röhrbein}

KI - Künstliche Intelligenz

German Journal on Artificial Intelligence - Organ des Fachbereichs "Künstliche Intelligenz" der Gesellschaft für Informatik e.V.

ISSN 0933-1875

Künstl Intell

DOI 10.1007/s13218-013-0276-X

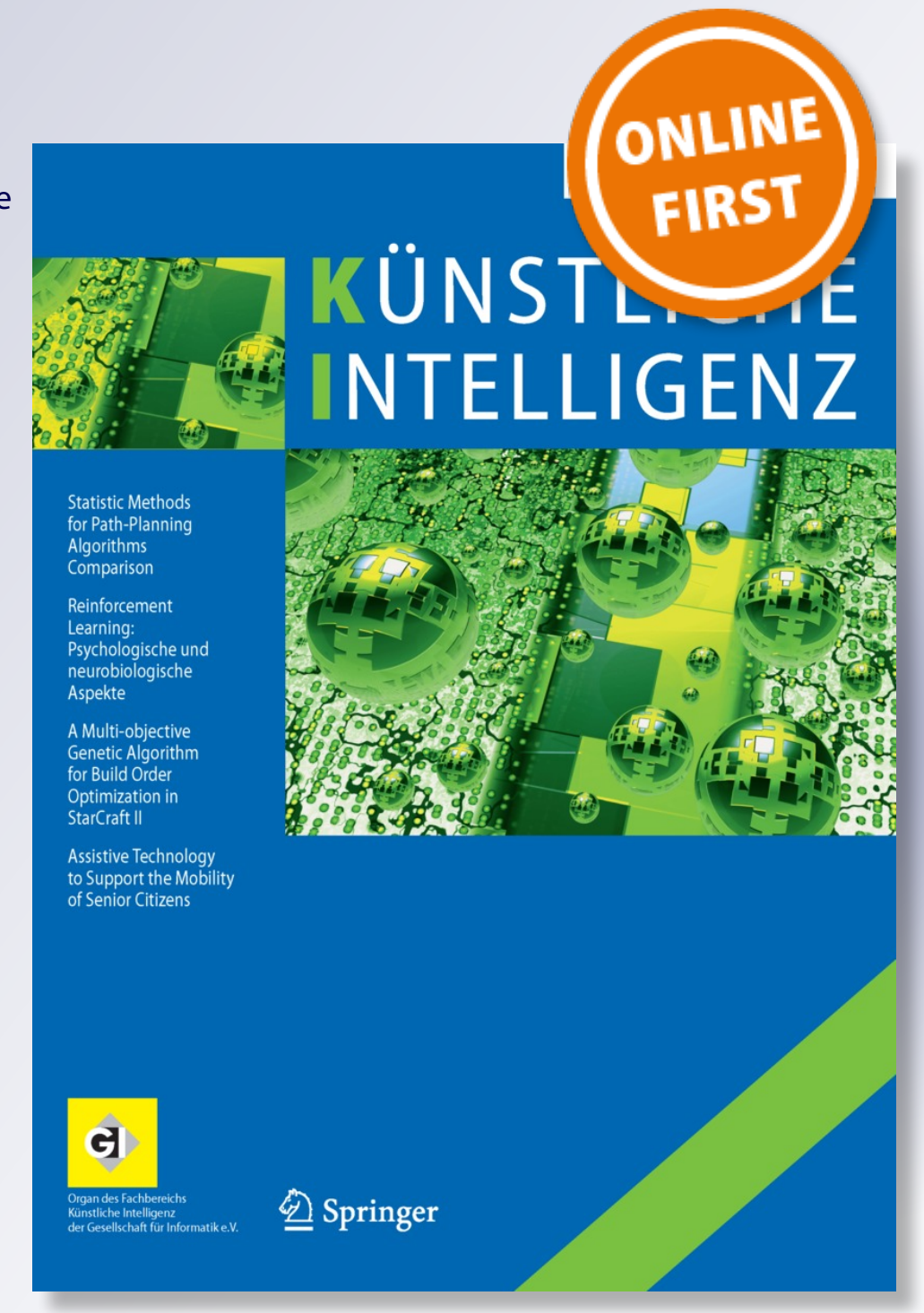

脰 Springer 
Your article is protected by copyright and all rights are held exclusively by SpringerVerlag Berlin Heidelberg. This e-offprint is for personal use only and shall not be selfarchived in electronic repositories. If you wish to self-archive your article, please use the accepted manuscript version for posting on your own website. You may further deposit the accepted manuscript version in any repository, provided it is only made publicly available 12 months after official publication or later and provided acknowledgement is given to the original source of publication and a link is inserted to the published article on Springer's website. The link must be accompanied by the following text: "The final publication is available at link.springer.com". 


\title{
Technology Transfer in Academia-Industry Collaborations
}

\author{
Interview with Dr. Alexander Waibel, Professor of Computer Science at Carnegie \\ Mellon University, USA and Karlsruhe Institute of Technology (KIT), Germany
}

\author{
Sascha Griffiths • Florian Röhrbein
}

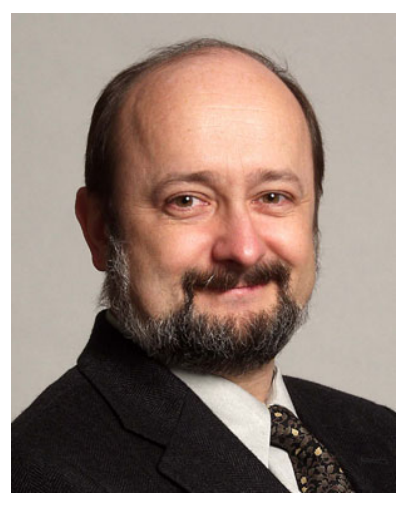

Dr. Alexander Waibel is a Professor of Computer Science at Carnegie Mellon University, Pittsburgh and at the Karlsruhe Institute of Technology, Germany. $\mathrm{He}$ is the director of the International Center for Advanced Communication Technologies, a joint center at eight international research institutions worldwide. The Center develops multimodal and multilingual human communication technologies that attempt to improve human-human and human-machine communication. Dr. Waibel has directed and coordinated many research programs in the field in the US, Europe and Asia. He has received several awards for pioneering work on multilingual speech communication and translation technology. The latest of his ventures, built the world's first speechto-speech translator on a phone, Jibbigo, and deploys its technologies in humanitarian and disaster relief missions. We spoke with him at ICRA in Karlsruhe on May 17, 2013.

This interview has been conducted in the context of a Structured Dialog between European research institutions and industrial partners in robotics. It is part of the ECHORD project, funded by the EC, FP7-ICT-231143 ECHORD.

S. Griffiths $(\bowtie) \cdot$ F. Röhrbein

Department of Informatics VI, Technische Universität München, 85748 Garching, Germany

e-mail: sascha.griffiths@in.tum.de
KI: The topic of our conversation will be academiaindustry collaboration and technology transfer. Can you tell us about your background, about things you have done in the past that had to do with technology transfer?

I have of course been an academic all my life. So, after my graduate studies I essentially stayed at the university and became a professor. But what has been clear relatively early on was that I did not want to do something that would just end up in reports that nobody reads. And it became a real concern to me to create technology that actually reaches people and transforms society. Technology is something that I find interesting and, personally, obviously rewarding to work on. But at the same time I always have a concern that we do things to improve the world that we live in. So I started companies, because to me that is a very healthy mechanism of transferring creations to society. At the same time these creations then raise new questions that we do science on.

In some sense a guiding light for all of my scientific work was always to find out which problems actually arise from practical goals that we try to pursue. If something you build turns out not answering the questions or not solving the problem that again triggers new questions. For example, when speech translation came about, people thought it was a crazy idea. But for me it clearly was something that people needed to communicate. If you let your scientific work be driven by a practical goal, by a practical vision, it raises all the right questions, and it gives you a chance to evaluate whether you are making progress. Otherwise people go to conferences and look at what other people do and then do the same things. And that is really not how we drive science forward. We have to orient science towards problems that are solving societal problems. This will raise the right scientific questions and it will create the worry about how to transfer it to society. 
Technology transfer can of course be done in various ways. Either you work as an academic and try to transfer what you do to companies. Or you write reports in the hope that somebody will read them. Or you form companies. In my opinion this is one of the best mechanisms to make technology transfer happen. When you write reports it is a bit optimistic to assume that people will anxiously read them and then make products. Collaborations between industry and universities very often suffer because there is still a large gap between basic research at universities and industrial exploitation. Usually, a new technology needs to be developed and then somebody has to prove that there is a market for it. And that takes a lot of effort and time. Small companies are better equipped for this. A large company typically is not interested when there is a small market and a small effort-unless it is in the hundreds of millions. There needs to be a transfer mechanism in between. Small companies are ideal for this, as the people who run them have an interest. Eventually, if the technology transfer is successful, there is a healthy mechanism to go from basic research to large-scale societal exploitation.

KI: So you think that small companies are the key to making the gap between research at academic institutions and the industry smaller?

Yes. Particularly if small companies grow from universities the entrepreneurs really understand the technology. They may have a great but unproven idea. For a large company it would be way too risky to build an effort around every new idea. When an entrepreneur manages to make a small company grow they prove in the process that this is actually something valuable. If they then get acquired or absorbed into a larger company, then that is a very natural way of transferring something that has proven to have market value into something large.

But there are also other mechanisms, as for example collaborative work with companies. This can work, but here again it is crucially important that the people who are on the industrial or commercial side of it really care to bring it into reality. Oftentimes you have projects in which the scientific partners only care about their publications and the commercial partners only care about the funding or about being part of a project.

\section{KI: What does academia have to offer to a firm?}

First of all, we are in the business of training students. Most of the time, people think that technology is the reports or the software. But the software and the reports are essentially rather worthless. The most important thing is what happens in people's brains. If you hire somebody who really knows what they are doing, that is the most brilliant and the fastest way to create technology that also moves into products. If we manage to transfer people from learning it in an academic environment into actually production of products, that is the best way of creating technology transfer. Start-up companies are another way for people who invented a technology. They care about their idea, and they understand it, so they are optimally equipped to actually turn it into a product.

KI: So, people are essentially the strength of industryacademia collaborations?

At least they should be. In my opinion this is the strongest part. Academic work is of course supposed to be more innovative in terms of creating new ideas. Ideas that are unproven, maybe crazy ideas that industry cannot afford to pursue. But that is a gray area. There are also large companies with very active research labs, which sometimes can be more academic than universities. Putting big companies in the product corner and universities in the theory corner is not doing justice to what is actually going on.

KI: This seems to be one of the main hurdles. Universities sort of have a long-term vision and look into the future, whereas big companies and corporations look for profit. And small companies are even more desperate to turn it into profit quickly. How do you think one can bring those two worlds together?

I think the most important issue is whether people care about the process. If academics really care about seeing the technology going to society there are mechanisms to do it. Often academics are happy to be in their academic corner and write their papers. Our academic promotion system emphasizes this. It is all about publications and showing how many papers you wrote. It does not necessarily look at whether people create something practical. And the same is a problem with students. When we train students they need to do theses. It is difficult to do a PhD or Master's thesis by building a system that is very product-oriented or practical. In some sense we are discouraging people from actually doing something practical at universities. Very often students just want to get their scientific work done and then leave. However, if tech transfer is properly addressed and one really does make an effort to make it happen, a university does have more freedom to explore different ideas and to really be on a high-risk-, and potential high-benefit side of things. Nobody will be too angry if some idea does not work out.

On the commercial side though, in my experience, transition works best if, in the case of collaborative projects between industry and academia, you put together teams of people who really care about the things that they do. Too often people pay lip service to the transition but are not really serious about it. And as I said before, another very good mechanism is through start-up companies getting absorbed in larger corporations, which to me is a very healthy process.

KI: So, you start something at university and it becomes a spin-off. But how does it reach the large corporation? By the corporation buying the SME, or just by creating the market? 
It can happen either way, for better or for worse. It happens either by buying the company, which is the healthy thing because you get the people along with the technology. Sometimes it happens by stealing the technology. Some large corporations shamelessly copy ideas. And in some cases there can be licensing agreements. But in my opinion the best way is actually in the heads of people. So there is a personal relationship between the innovators and the commercial exploitation. That is usually the fastest and most efficient way to do it.

KI: We have different measures for success: As you said, academics are looking for that long publication list. It is in the nature of the game that companies are looking for profit. But in cooperative projects, where industry and academia come together to work on something, how would you measure success and progress?

That depends on the setup of the project. In a very scientific project there are scientific goals. In my opinion metrics should always be chosen or developed around a practical goal. You need to measure whether the planned progress is actually attained. The different players in the team do their part in order to make that happen.

Scientific projects often stop there. One problem is that, in order to get funded, they have to be so innovative that there cannot possibly be a product in three years. But everybody says that they are going to make a contribution to a product-because that is the official goal. By the end of a project there are usually good prototypes. But to go from a prototype to a commercially usable product takes considerable work. And that is usually where funding is very difficult to come by. Because you now have to care about boring tasks, like scaling it up, making it work on different operating systems, making sure it runs faster, or on different software platforms. You have to worry about the distribution channels, about payment schedules and payment mechanisms. There is a ton of things you have to do before you can actually deliver a product - and the usual scientific funding sources will not pay for these tasks. In fact it is illegal to get money for marketing or sales. This is usually a very difficult spot for entrepreneurs.

KI: So you propose to have task-level measures of success?

Yes. We look at the practical problems. For example, in our new project EU-BRIDGE we have a particular target: We want to make speech translation work better. We realized that the problem is not only the recognition accuracy, but also proper punctuation. So we turned that into a measure: We let a human put in the proper punctuation in a text, and then measure how well our software can achieve that. This way we can create a metric that pursues a practical goal.

KI: Would you agree that the closer you get to a product the less interested the academics get? Rodney Brooks said in an interview ${ }^{1}$ with us 'If you reach technological readiness level six, academics have long lost interest by that point.'

(Laughs) Cautiously I would agree. Academics lose interest when their students lose interest. And students lose interest when they cannot graduate anymore with what they do. That means: What can we let people graduate with? You can get a $\mathrm{PhD}$ for making a new analysis, a new study, a new discovery, or even a new implementation. But for just transferring something from one operating system to another you typically can't. But a company still has to do that in order to be successful on the market. When the task is development, and not research anymore- that is where you tend to lose the academics. But if you look properly you usually discover areas of concern which are so 'hard' that -if properly formulated-they create a new research task.

Here is an example: We built a translator that works for English and Spanish and for three more languages. But there are six thousand languages in the world. We cannot pay for that many languages. And in many languages, like Iraqi, you cannot get any databases because the language is not written. So, we need to find a process to make building new language systems cheaper. From that observation we have formulated all kinds of new PhD theses. For example: Can you infer a parallel corpus just by speech? Can you infer words just from reading speech, if you know that it is a translation of it? Can you build a recognizer in a week, instead of in a year? And so on.

So, if you decompose this practical problem into something that points to the actual challenge limiting it, you will discover quickly that actually it consists of very hard academic problems. And these academic problems we can answer in an academic way. For me that is an exciting part about being an academic. We can say to a student: 'This is a hard problem. It will take years to figure out. Why don't you have a go at it?' To me personally this gives me great satisfaction. We are not doing it because it is fashionable on a conference, but we are doing it with a purpose in mind.

KI: How does technology transfer differ in Europe and America?

I live in both continents and in both systems, so I am keenly aware of the pros and cons. In fact I cannot completely let go of either of these systems because I see the advantages and the problems all too well. Generally speaking I think Europe tends to be more long-term oriented, and it has longer term funding. American funding models have become very short-term oriented. Also, the American approach tends to be very pragmatic. It is very quick to change course when things work or do not work.

In terms of technology transfer, there are very different models. The European model tends to have collaborative

\footnotetext{
${ }^{1}$ See http://robohub.org/tag/echord-interview-series.
} 
projects with industry and academic players. In the US there tend to be research projects with individual players, where you do not distinguish whether they are commercial or industrial. You just work on a particular target. One very important difference is the funding mechanism. In the US a large amount of the scientific funding comes from the Department of Defense. In my opinion this is an advantage in the US, because the funding institution also is the customer. This means there is someone who really wants the technology at the end of the research project.

\section{KI: Is the commercialization step harder in Europe?}

No, because the goal of European projects is commercialization. So there is not only tolerance but a mission to do it. But the mechanism is a bit awkward, because the institution you are working for is not the institution taking your results. So in some sense you have to create your own customers in order to be successful. And this creates more responsibility for the partners.

\section{KI: Where is the market easier for SMEs and start-ups?}

You can start companies in all parts of the world. In America I can start a company in one hour and in Germany it takes a week. That is not the problem. The problem is, how do you get funding? In other words, is there a culture of venture capitalism or business angels? Another thing every VC in America will talk about is the exit strategy. How will you get out of this company? In Germany you do not talk about this. You call somebody who starts a company an Existenzgründer. It's a totally different concept. Somebody starting a company in Germany is considered to be starting an existence that way. In this word embedded there is already the notion that their grandchildren will still work in this company. In America nobody has an illusion it will last that long. If you think about transition being so rapidly paced you better be out of that company again in five years.

So, the challenge in Europe is not just the funding, but how transfer can happen after the company has been successful. Doing an IPO in Europe is really difficult. Mergers and acquisitions do not happen very often.

KI: What is your impression about robotics in Europe and America?

There are many differences, especially in the robotics area. Obviously Japan also has to be mentioned here. Japan has been extremely active, particularly in the area of humanoids. And they have a much more open vision to robots that are human-like. Europeans have been more resistive and Americans are probably more concerned with robots that fulfill practical missions. This playfulness of robotics in Japan is quite interesting and innovative. It is good to see that in Europe large programs have been underway, and they do generate a great deal of innovation. Of course US robotic efforts are much more oriented again towards the sponsors and the customers. The missions tend to be in the disaster or military area, while European efforts again tend to be more commercially oriented. This is a natural by-product of the funding structures in both countries. In both America and Europe outstanding robotics research has been done with very impressive results. These results wind up merging again.

So I think although funding initially comes from different sources, at the end of the day, once the technology is created, people transfer it in similar ways.

KI: Thank you very much for this interview. 